\title{
Left ventricle to pulmonary artery conduit in treatment of transposition of great arteries, restrictive ventricular septal defect, and acquired pulmonary atresia ${ }^{1}$
}

\author{
A. K. Singh, J. Stark, and J. F. N. Taylor \\ From The Thoracic Unit, Hospital for Sick Children, Great Ormond Street, London
}

Progressive cyanosis after banding of the pulmonary artery in infancy occurred in a child with transposition of the great arteries and a ventricular septal defect, and a Blalock-Taussig shunt operation had to be performed. At the time of correction a segment of pulmonary artery between the left ventricle and the band was found to be completely occluded so that continuity between the left ventricle and the pulmonary artery could not be restored. A Rastelli type of operation was not feasible as the ventricular septal defect was sited low in the muscular septum. Therefore, in addition to Mustard's operation, a Dacron conduit was inserted from the left ventricle to the main pulmonary artery to relieve the obstruction. Postoperative cardiac catheterization with angiocardiography indicated a satisfactory haemodynamic result. The patient remains well 11 months after the operation. This operation, a left ventricle to pulmonary artery conduit, may be used as an alternative procedure in patients with transposition of the great arteries, intact interventricular septum, and obstruction to the left ventricular outflow, if the obstruction cannot be adequately relieved.

Infants with transposition of the great arteries and ventricular septal defect may be treated either by early closure of the ventricular septal defect and Mustard's operation or by pulmonary artery banding in infancy followed by later correction (Stark et al., 1970; Neutze and Clarkson, 1973; Stark, 1973; Subramanian, 1973; Trusler and Mustard, 1974).

An unusual complication of pulmonary artery banding occurred in a child with transposition of the great arteries plus ventricular septal defect who had had the pulmonary artery banded in infancy. Subsequently a Blalock-Taussig anastomosis had been performed because of increasing cyanosis. A segment of pulmonary artery between the left ventricle and the band had become completely occluded, so that at the time of correction continuity between the left ventricle and pulmonary artery could not be restored. A Rastelli type of operation was not feasible because the ventricular septal defect was small and located in the lower part of the muscular septum. Therefore, in addition to Mustard's operation, a Dacron conduit was inserted ${ }^{1}$ This work was supported in part by a grant from the British Heart Foundation. from the left ventricle to the main pulmonary artery to relieve the obstruction.

\section{Case report}

This male infant was the product of a normal pregnancy and delivery and weighed $3.3 \mathrm{~kg}$ at birth. Cyanosis was present from birth and he suffered recurrent chest infections and failed to gain weight in the early months of life. Examination showed a moderate degree of cyanosis with a harsh systolic murmur along the left sternal border. Chest $x$-ray examination showed an enlarged heart and pulmonary plethora. The infant was digitalized and cardiac catheterization with angiocardiography were undertaken at the age of 25 days. A diagnosis of transposition of the great arteries, ventricular septal defect, and pulmonary hypertension (Table 1) was made. Attempted balloon atrial septostomy was unsuccessful. Recurrent chest infections and congestive cardiac failure prevented his discharge home and at the age of 10 months he was referred to this unit. Examination revealed a small, cyanosed infant with digital clubbing, tachypnoea, and tachycardia. A systolic murmur was heard over the praecordium. The liver was enlarged $3 \mathrm{~cm}$ below 
TABLE 1 Catheterization data

\begin{tabular}{|c|c|c|c|c|c|}
\hline Site & 3 weeks & 10 months & $\begin{array}{l}10 \text { months } \\
\text { (after Blalock-Hanlon } \\
\text { procedure) }\end{array}$ & 2 years & $\begin{array}{l}6 \frac{1}{2} \text { years } \\
\text { (patent Blalock-Taussig } \\
\text { shunt) }\end{array}$ \\
\hline \multicolumn{6}{|l|}{ Pressures $(m m H g)$} \\
\hline Right atrium (mean) & & 7 & 0 & 4 & 5 \\
\hline Right ventricle & $55 / 5$ & $84 / 2-12$ & $80 / 3$ & $100 / 6$ & $110 / 4$ \\
\hline Aorta & $55 / 18$ & $88 / 64$ & $80 / 44$ & $96 / 66$ & $110 / 50$ \\
\hline Left atrium (mean) & & 10 & 0 & 5 & 4 \\
\hline Left ventricle & $48 / 0$ & $80 / 0-9$ & $70 / 5$ & $120 / 20$ & $240 / 2$ \\
\hline Main pulmonary artery & $48 / 24$ & $60 / 30$ & 7028 & $120 / 20$ & Not entered \\
\hline $\begin{array}{l}\text { Pulmonary artery distal to band } \\
\mathrm{O}_{2} \text { saturation }\end{array}$ & & & & $1210^{\star}$ & $20 / 16 \dagger$ \\
\hline Aorta & 33 & 44 & 74 & 47 & 85 \\
\hline
\end{tabular}

^Right pulmonary artery.

†Via Blalock-Taussig anastomosis.

Conversion from Traditional to SI Units: $1 \mathrm{mmHg} \approx 0.133 \mathrm{kPa}$.

the costal margin. The electrocardiogram showed right ventricular hypertrophy and the chest $x$-ray film showed an enlarged heart with pulmonary plethora. Haemoglobin was $15 \mathrm{~g} / \mathrm{dl}$.

Further cardiac catheterization confirmed the diagnosis of transposition of the great arteries and ventricular spetal defect. The aortic oxygen saturation was 44 per cent; A Blalock-Hanlon procedure was therefore performed, and the arterial oxygen saturation rose to 74 per cent. As he remained in congestive cardiac failure another cardiac catheterization was performed two weeks later which confirmed that a high pulmonary flow was present with a high pulmonary artery pressure (Table 1). The pulmonary artery was, therefore, banded. After this he improved and was discharged from hospital on a maintenance

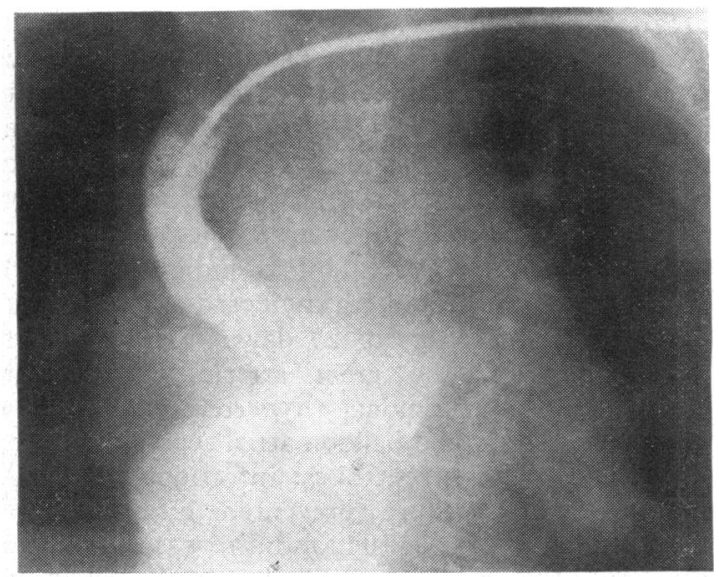

FIG. 1 Angiogram after injection into superior vena cava. Systemic venous atrium and superior and inferior venae cavae are opacified. dose of digoxin. During the next year his general condition improved.

He was readmitted at the age of 2 years because of sudden deterioration. At this time central cyanosis with clubbing was increased and the systolic murmur was still audible over the left sternal border. The liver was enlarged $4 \mathrm{~cm}$ below the costal margin. The haemoglobin was now $22 \mathrm{~g} /$ dl. His general condition indicated a low cardiac output. Repeat cardiac catheterization (Table 1) showed an aortic saturation of $\mathbf{4 7}$ per cent.

A right Blalock-Taussig shunt was subsequently performed. Cyanosis decreased and the aortic saturation rose to 78 per cent. He was seen regularly in the follow-up clinic and remained well and active with a good exercise tolerance.

At the age of $6 \frac{1}{2}$ years he was admitted electively for reinvestigation with a view to correction. Examination revealed mild cyanosis and clubbing. There was biventricular hypertrophy with a thrill and grade 4/6 pansystolic murmur along the left sternal border. The haemoglobin was $16 \mathrm{~g} / \mathrm{dl}$. Cardiac catherization with angiography showed transposition of great arteries with a minimal leftto-right shunt through a low, muscular ventricular septal defect. The pulmonary artery filled only through the patent Blalock-Taussig anastomosis (Table 1).

The operation was performed at the age of 6 years and 11 months, using cardiopulmonary bypass. The right Blalock-Taussig shunt was ligated. While the pulmonary artery was being dissected, the right coronary artery was inadvertently opened because of dense adhesions and then repaired with 6-0 Prolene. The segment of pulmonary artery between the band and pulmonary valve was fibrosed and completely occluded. The left ventricle was 
TABLE 2 Postoperative catheterization

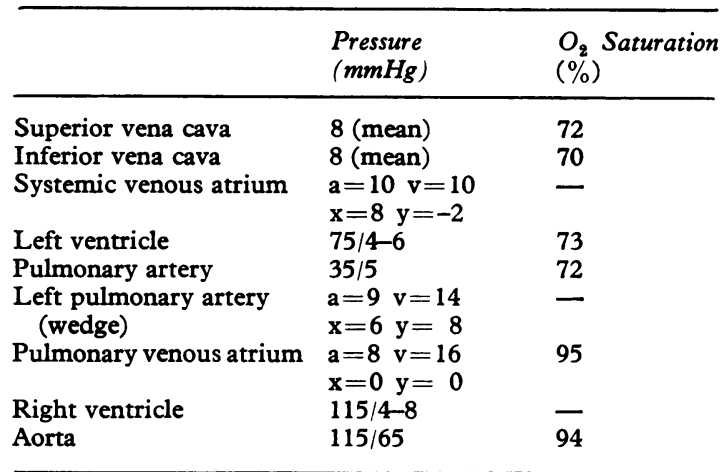

Conversion from Traditional to SI Units: $1 \mathrm{mmHg} \approx 0.133 \mathrm{kPa}$.

then opened to visualize the left ventricular outflow tract. There was no outlet from the left ventricle to the pulmonary artery. As neither a Hancock prosthesis nor an aortic homograft was available a No. 20 valveless Dacron tube was sutured to the left ventriculotomy site between branches of coronary arteries and connected to the distal end of the main pulmonary artery, using a 4-0 Prolene running stitch. A standard Mustard procedure was then performed using a pericardial patch. The ventricular septal defect was left open to act as a vent for the hypertrophied left ventricle in case the conduit became partly obstructed. The patient came off bypass without difficulty, haemostasis was achieved, and the chest was closed in a routine manner. After the operation he was ventilated and the circulation was maintained with minimal support from inotropic agents. He was given digitalis and the other inotropic agents were discontinued 72 hours later. He was extubated on the fifth postoperative day. Diuretics were given because of fluid retention. He remained well and was discharged 3 weeks after operation.

The child was readmitted for evaluation, including cardiac catheterization, 4 months later. $\mathrm{He}$ was pink and his exercise tolerance was much improved. He was taking digoxin only. A grade $4 / 6$ systolic murmur was audible over the praecordium and the liver edge was felt $2 \mathrm{~cm}$ below the costal margin. The lungs were normal. Haemoglobin was $13 \mathrm{~g} / \mathrm{dl}$. The electrocardiogram showed sinus rhythm with right ventricular hypertrophy. The results of cardiac catheterization are shown on Table 2. No intracardiac shunt was detected at atrial or ventricular level, the superior and inferior venous pathways were unobstructed (Fig. 1) and the patency of the right coronary artery was confirmed. The conduit which leads from the left ventricle to the main pulmonary artery was patent, with mild to moderate regurgitation (Fig. 2). The left ventricle ejected almost all the regurgitant portion of contrast material early in the subsequent systole. Both ventricles showed a normal pattern of contraction over the angiocardiogram.

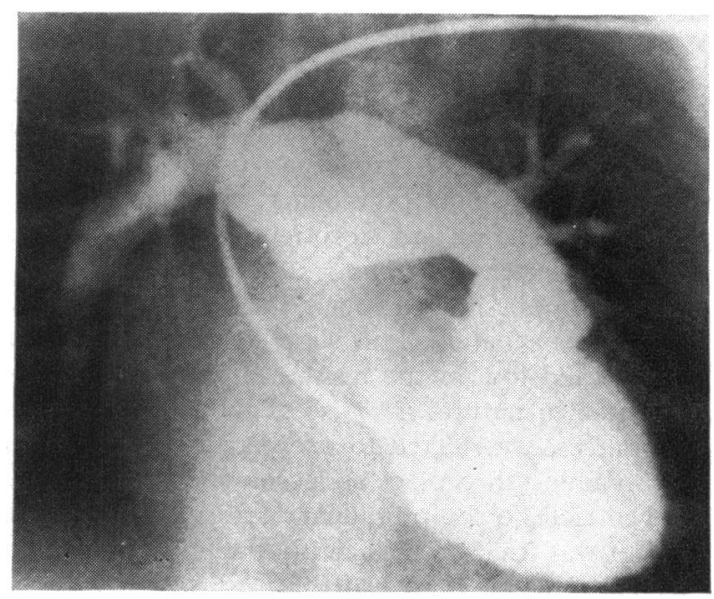

A

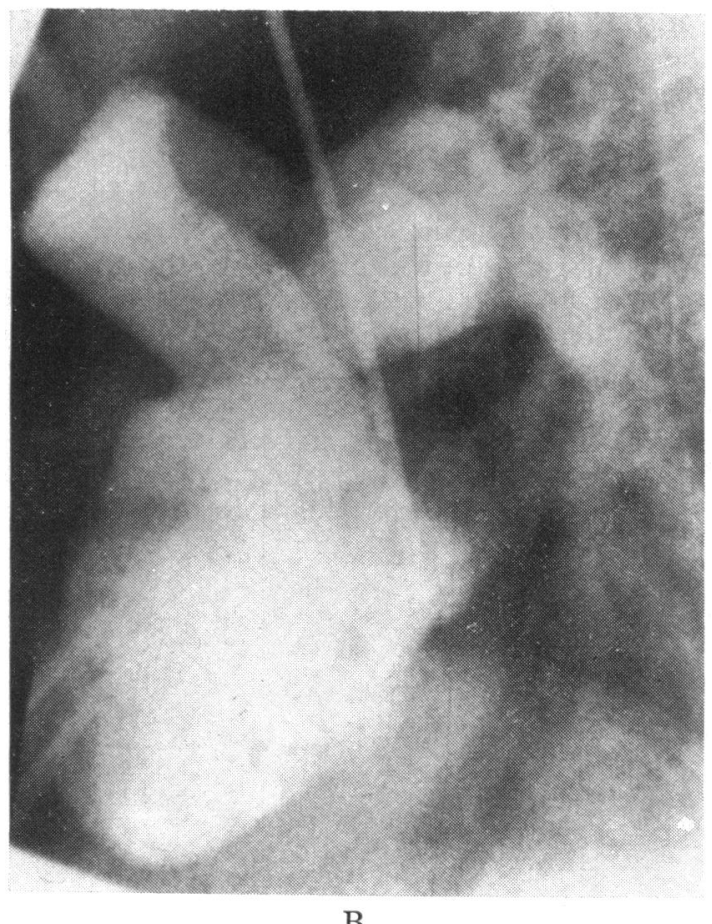

$\mathrm{B}$

FIG. 2 Left ventricular angiocardiogram. A) Anteroposterior projection; left ventricle, conduit, and main pulmonary artery are shown. B) Lateral view. Note that the conduit is placed in front of the ascending aorta. 
At present, 11 months after the operation the child remains well. $\mathrm{He}$ is fully active and on no medication. The heart is still slightly enlarged and a $3 / 6$ systolic murmur can be heard over the praecordium.

\section{Discussion}

Occlusion of the main pulmonary artery is a rare complication after banding of the pulmonary artery (Dobell et al., 1973). In our patient the pulmonary valve and the main pulmonary artery were completely obliterated and fibrotic after the previous pulmonary artery banding.

It was impossible to repair the main pulmonary artery with a patch. The ventricular septal defect was situated low in the muscular septum and was restrictive in nature. Because of these unusual circumstances, we elected to proceed with Mustard's operation and then place a Dacron conduit from the left ventricle to the pulmonary artery. A valveless conduit was used because neither a homograft nor a heterograft valve was available.

This approach may perhaps be used in other patients. In several patients with transposition of the great arteries, intact ventricular septum, and left ventricular outflow tract obstruction, we were unable to remove the obstruction completely. This was especially so in patients with a redundant mitral valve or a long fibromuscular type of obstruction. So far these patients seem to tolerate a high left ventricular pressure with gradients of 80 to $90 \mathrm{mmHg}$ $(10.6$ to $12.0 \mathrm{kPa})$ well. Should they deteriorate later, a left ventricular to pulmonary artery conduit seems to be a logical solution. Attempts to treat patients with transposition of the great arteries, intact ventricular septum, and left ventricular outflow tract obstruction by creating a high ventricular septal defect and performing a Rastelli operation were unsuccessful (Danielson et al., 1971). A conduit from the posterior ventricle has been used recently by Bernhard, Poirier, and LaFarge (1975). They inserted a valve containing a conduit between the left ventricle and descending aorta in a patient with congenital aortic stenosis and hypoplasia of the aortic valve annulus.

\section{References}

Bernhard, W. F., Poirier, V., and LaFarge, C. G. (1975). Relief of congenital obstruction to left ventricular outflow with a ventricular-aortic prosthesis. Fournal of Thoracic and Cardiovascular Surgery, 69, 223.

Danielson, G. K., Mair, D. D., Ongley, P. A., Wallace, R. B., and McGoon, D. C. (1971). Repair of transposition of the great arteries by transposition of venous return. fournal of Thoracic and Cardiovascular Surgery, 61, 96.

Dobell, A. R. C., Murphy, D. A., Poirier, N. L., and Gibbons, J. E. (1973). The pulmonary artery after debanding. Fournal of Thoracic and Cardiovascular Surgery, 65, 32.

Neutze, J. M., and Clarkson, P. M. (1973). Transposition of the great arteries in infancy. In Heart Disease in Infancy: Diagnosis and Surgical Treatment, p. 266. Ed. by B. G. Barratt-Boyes, J. M. Neutze, and E. A. Harris. Churchill Livingstone, Edinburgh.

Stark, J. (1973). Primary definitive intracardiac operations in infants: transposition of the great arteries. In Advances in Cardiovascular Surgery, p. 101. Ed. by J. W. Kirklin. Grune and Stratton, New York.

Stark, J., Tynan, M., Tatooles, C. J., Aberdeen, E., and Waterston, D. J. (1970). Banding of the pulmonary artery for transposition of the great arteries and ventricular septal defect. Circulation, 41 and 42, Suppl. 2, 116.

Subramanian, S., and Wagner, H. (1973). Correction of transposition of the great arteries in infants under surfaceinduced deep hypothermia. Annals of Thoracic Surgery, 16, 391.

Trusler, G. A., and Mustard, W. T. (1974). Palliative and reparative procedures for transposition of the great arteries. Annals of Thoracic Surgery, 17, 410.

Requests for reprints to Dr. J. Stark, Thoracic Unit, The Hospital for Sick Children, Great Ormond Street, London WC1N 3JH. 